\title{
Do No Harm: Challenges in Organizing Psychosocial Support to Displaced People in Emergency Settings
}

\author{
Michael G. Wessells
}

\section{Abstract}

Psychosocial assistance in emergencies plays an important role in alleviating suffering and promoting well-being, but it is often a source of unintended harm. A prerequisite for ethically appropriate support is awareness of how psychosocial programs may cause harm. This paper underscores the importance of attending to issues of coordination, dependency, politicization of aid, assessment, short-term assistance, imposition of outsider approaches, protection, and impact evaluation. With regard to each of these issues, it suggests practical steps that may be taken to reduce harm and maximize the humanitarian value of psychosocial assistance.

\section{Résumé}

L'assistance psychosociale dans des situations d'urgences joue un rôle important dans le soulagement de la souffrance et la promotion du bien-être; mais, souvent, elle est la source de préjudices non intentionnels. Une connaissance de la façon dont les programmes psychosociaux peuvent causer des préjudices est un préalable pour un support éthiquement convenable. Cet article souligne l'importance de la prise en considération des problèmes liés à la coordination, la dépendance, la politisation de l'aide, l'évaluation, l'assistance à court terme, l'imposition des approches par des personnes extérieures, la protection, et l'évaluation de l'impact. Il suggère des mesures pratiques qui peuvent être prises par rapport à chacun de ces problèmes pour réduire les préjudices et optimiser la valeur humanitaire de l'assistance psychosociale. L'assistance psychosociale dans des situations d'urgences joue un rôle important dans le soulagement de la souffrance et la promotion du bien-être; mais, souvent, elle est la source de préjudices non intentionnels. Une connaissance de la façon dont les programmes psychosociaux peuvent causer des préjudices est un préalable pour un support éthiquement convenable. Cet article souligne l'importance de la prise en considération des problèmes liés à la coordination, la dépendance, la politisation de l'aide, l'évaluation, l'assistance à court terme, l'imposition des approches par des personnes extérieures, la protection, et l'évaluation de l'impact. Il suggère des mesures pratiques qui peuvent être prises par rapport à chacun de ces problèmes pour réduire les préjudices et optimiser la valeur humanitaire de l'assistance psychosociale.

$\mathrm{F}$ or many years, psychosocial support to refugees and internally displaced people was viewed through the lens of Maslowian psychology ${ }^{1}$ as a second-tier operation, something to be done after one had met people's basic survival needs in an emergency. More than any other single event, the December 2004 tsunami showed that the psychosocial effects of catastrophic events are not secondary but primary dimensions of the lived experience of emergencies. For a child who had hoped for a good life but who in a matter of minutes lost her home, family, village, belongings, and many friends, the psychosocial shocks were not secondary to her material losses or things to be dealt with later. This brief but catastrophic moment convinced the world that psychosocial support ought to occur at the same time one applies the most immediate life-saving measures in areas such as health, water and sanitation, shelter, and food aid. 
This increased priority of psychosocial interventions is owed in part to the professionalization of the field of psychosocial assistance to displaced people. This trend is evident in three respects. First, there is a rapidly growing literature on the psychosocial impact of forced migration that spans multiple continents, age groups, and kinds of vulnerability and that increasingly takes into account issues of gender, class, and culture. ${ }^{2}$ Second is an expanding array of promising practices in supporting displaced people $\mathrm{e}^{3}$ and increased attention to the importance of documenting the impact of psychosocial programs. ${ }^{4}$ Third is the development of global, inter-agency guidance regarding psychosocial support. Following a mandate from the Inter-Agency Standing Committee (IASC), twenty-seven UN agencies and consortia of non-governmental agencies (NGOs) have recently constructed the first global guidance on the minimum response to mental health and psychosocial support needs in emergency settings. ${ }^{5}$ This guidance simultaneously points practitioners in the directions that have proven most effective and cautions against harmful practices.

Despite the increased professionalization and legitimacy of the field of psychosocial assistance to displaced people, there are significant, ongoing concerns about respect for the humanitarian imperative "Do No Harm.” In nearly every emergency, unnecessary harm is caused by the very humanitarian operations that are intended to support affected people. ${ }^{6}$ One of the main factors that enables harm is the paucity of systemic evidence regarding which psychosocial interventions work or are most effective per dollar of investment. Although the field of psychosocial assistance shows increasing professionalization, it does not have the impressive array of proven interventions visible in humanitarian sectors such as health. In the absence of hard evidence, psychosocial interventions are often guided by preconceptions, personal preferences, and ideologies rather than by applied science that takes into account the unique historical, political, cultural, and social realities of the affected people and their situation. Too often, emergencies serve as a testing ground in which well-intentioned psychologists, including those who have little or no field experience, ply their latest tools, most of which have not been validated in the local context.

The likelihood of causing harm owes much to myriad factors such as the competitive structure of the humanitarian enterprise, uncertainties about its fundamental goals and orientation, ${ }^{7}$ the power differential between outside agencies and local people, ${ }^{8}$ the complexities of local culture and politics ${ }^{9}$ not to mention the complexities of humanitarian politics, ${ }^{10}$ and the lack of appropriate training for international psychosocial workers. Also, most professional codes of ethics and institutional review boards, nei- ther of which were designed with large-scale emergencies and diverse cultures and situations in mind, offer scant guidance or oversight. For most humanitarian workers, the author included, the pressures of an emergency overwhelm the propensity for self-reflection. The sad irony is that without critical self-reflection, one is unlikely either to see the inadvertent harm one causes or to take the steps needed to correct and prevent harm.

This paper aims to identify some of the main ways in which psychosocial interventions cause harm and to offer concrete suggestions regarding how to prevent harm. It seeks to avoid denigrating the field of psychosocial support or paralyzing workers by suggesting that psychosocial programs inevitably do more harm than good. Rather, its goal is to offer constructive criticism that strengthens psychosocial work by helping to prevent unnecessary harm. My core assumption, derived largely from field experience, is that much harm can be prevented through a mixture of critical self-awareness and action. With this in mind, I will examine seven key issues, which are not exhaustive but which arise repeatedly and warrant immediate attention. For purposes of simplicity, each issue will be examined separately, though in practice some of the greatest harm occurs through their interaction. For each issue, I will identify practical steps that mitigate and prevent harm.

\section{Coordination}

It is axiomatic that large-scale emergencies present needs that are too great to be met by any single agency and that inter-agency collaboration and coordination are necessary. ${ }^{11}$ Accordingly, UN agencies or satellite agencies organize coordination groups to enable effective collaboration, protect human rights, and achieve appropriate levels of quality and coverage in the humanitarian response.

Nevertheless, poor coordination continues to be the Achilles heel of nearly every emergency operation. Coordination problems arise largely from the structure of the humanitarian enterprise, in which agencies compete for the same limited funds and often seek to gain comparative advantage by not sharing information and not relinquishing their advantage through collaboration. That poor coordination causes harm is evident is the waste of scarce resources due to duplications of effort, the failures to share information and to learn from each other, the uneven coverage of geographic areas having significant humanitarian need, and failure to deliver comprehensive support.

Psychosocial workers contribute to these issues in myriad ways. In Timor Leste (former East Timor) following the 1999 attack of the Indonesian paramilitiaries, many agencies conducted psychosocial work to support the population that had suffered mass displacement and destruction 
of homes and infrastructure. However, most humanitarian agencies stayed close to the capital city, Dili, where they had ready access to large numbers of people. The apparent motivations were to look good to donors by serving large numbers of people and to stay close to where the key resource allocation decisions were made rather than go to remote, rural areas that had enormous but unmet needs. Unfortunately, this tendency to maintain a prominent position in the centres of power limited geographic coverage and undermined the strategic allocation of resources that is at the heart of effective coordination. A similar pattern wherein agencies cluster near the capital is visible in most emergencies.

Significant coordination problems are also evident in failures to provide the diverse kinds of support needed to assist affected people. Most psychologists and psychiatrists accept the idea that in an emergency, supports should be organized according to the familiar intervention pyramid. ${ }^{12}$ At the top of the pyramid is a minority of people, typically around 10 per cent, who are severely affected or who had pre-existing problems such as chronic mental illness and who need specialized supports such as psychiatric care. The middle layer of the pyramid is a larger group, usually around 40 per cent of the population, who are at risk due to issues such as gender-based violence, separation from families, recruitment by armed groups, stigmatization and isolation, and exploitation through dangerous labour. These at-risk people, who often include the elderly, women, children, and people with disabilities, often benefit from focused psychosocial supports that trained paraprofessionals implement at the community level. The largest group - the 50 per cent at the base of the pyramid-typically requires no specialized or focused support and will function well and without severe distress through the provision of appropriate education, health, shelter, livelihood, and other basic supports. Within this framework, effective coordination requires the establishment of supports at each level of the pyramid and of appropriate referral mechanisms.

In reality, however, it is the exception rather than the norm to observe in emergencies proportionate supports at all three levels. In most emergencies in resource-poor countries, the most severely affected people have few supports. In emergencies in places such as Angola and Chad, it is not uncommon to see people who are chronically mentally ill tied to trees or other objects to prevent them from wandering and encountering harm. In other emergencies, there is a shortage of holistic, community-based supports to assist people at the middle and bottom layers of the pyramid.

Even if proportionate supports exist, the division in the field of psychosocial assistance into clinically oriented work and more community oriented work may produce poor coordination across the layers. In most emergencies, psychiatrists working with the WHO and government health agencies organize clinical services for the most severely affected people. Typically, psychologists and social workers who are coordinated by agencies such as UNICEF and UNHCR organize holistic community-based supports. In Kosovo, this polarization resulted in the establishment of two separate coordination groups, one under WHO and the other under UNHCR. The existence of separate subgroups is not problematic in itself, but it becomes an impediment if there are no communications across the subgroups and no cross-group referral mechanisms. Sadly, a visiting group of US psychiatrists, psychologists, and social workers learned that the two coordination groups neither collaborated with each other nor knew of each other's existence.

At present, this polarization of the field of psychosocial assistance poses significant challenges to the nascent Clusters system, in which the Health Cluster and the Protection Cluster share the coordination responsibilities for mental health and psychosocial support, working whenever possible with government partners. For example, soon after the 2006 earthquake in Yogyakarta, Indonesia, WHO, which plays a lead role in the Health Cluster, and the Indonesian Ministry of Health established a mental health coordination group. Independently, UNICEF, which plays a lead role in the Protection Cluster, established a child protection coordination group that included agencies conducting community-based psychosocial work. The problem was that initially the two groups did not attempt to coordinate. Although this situation was subsequently corrected, this example shows how the divisions in the field that antedated the Clusters approach can mitigate the effectiveness of the Clusters system. To address this problem, the new IASC Guidelines calls explicitly for the establishment of a single, overarching coordination structure. Psychosocial workers, too, can help to address the problem of poor coordination by doing their share to coordinate their work with others, participating in local coordination groups, and encouraging collaboration across different levels of the intervention pyramid.

\section{Dependency}

Two key parts of the foundation of humanitarian work are local empowerment and the restoration of dignity. ${ }^{13}$ Active engagement in planning and action to build a better life is widely regarded as one of the best antidotes to the feelings of helplessness and being overwhelmed that are prevalent in emergencies and camps for displaced people. Also, people's sense of dignity, which is diminished by war, losses, and status changes associated with emergencies, increases mark- 
edly as local people regain a sense of control and take active steps toward improving their lives. Whereas having a sense of agency bestows dignity and hope, feelings of dependency trample dignity and invite passivity and despair. Most community-based psychosocial programs aspire to mobilize and empower communities by activating local networks, encouraging participation, and building on the capacities that local people have. ${ }^{14}$ This empowerment-oriented approach emphasizes community resilience and avoids regarding local people as passive victims.

It is an understatement to say that many emergency psychosocial responses fall short of this ideal. Following the December 2004 tsunami, for example, a door-to-door survey in a village of fifty families in northern Sri Lanka indicated that there were twenty-seven different NGOs there "providing help." According to one local resident, "We never had leaders here. Most people are relatives. When someone faced a problem, neighbours came to help. But now some people act as if they are leaders, to negotiate donations. Relatives do not help each other any more." 15 This example illustrates the harm that occurs when the emphasis is on providing external supports rather than on building on the resources and supportive practices that already existed. Done badly, humanitarian aid undermines local supports at the very moment they need to be strengthened.

One of the most common pathways into dependency is tokenistic participation. Participation, which is a core human right, is authentic when local people have ownership over programs, take part in key decisions, and guide program design, implementation, evaluation, and refinement. In the heat of emergencies, however, participation is often relegated to the sidelines due to the emphasis on saving lives by providing emergency services. Often, NGOs create these services with little consultation with government actors or community leaders and members. For example, expatriate psychiatrists often provide services via international NGOs that create what amounts to a parallel system to that of the government for caring for severely affected people. Sadly, these parallel systems tend to collapse when the emergency funding dries up. With local people dependent on outside services that are unsustainable, the withdrawal of the services leaves needy people unsupported and quite possibly worse off than they might have been otherwise. As colleagues in Sri Lanka put it, the greatest shock of the tsunami was the influx of external actors who showed greater interest in garnering large grants than in building local capacities and partnering at a deep level with local communities and government actors. Cynically, they called this phenomenon the "golden tsunami," an epithet that ought to awaken all humanitarians to their responsibilities.
To avoid these problems, psychosocial workers should put capacity building, empowerment, and community mobilization at the heart of their program approach. Although in emergencies one sometimes hears agencies excuse themselves by saying "There was no time for a fully participatory approach," it is time to recognize that a participatory approach is both essential and feasible in most contexts.

\section{Aid as a Political Tool}

Humanitarian ethics require close adherence to the principle of impartiality, which calls for humanitarian workers and agencies to deliver aid where it is needed, without prejudice to particular political, military, ethnic, gender, class, or religious orientations. Also, there is widespread attention to the principle of independence, which requires humanitarian agencies not to take sides in a conflict and to avoid making humanitarian aid an extension of military operations.

These principles, however, are easier to state than to obey in practice. In every affected group of people, there are discernible subgroups that vie for power and influence. Not uncommonly, local people appropriate aid to the benefit of some groups over others, even using it to continue the fighting that had caused mass displacement in the first place. ${ }^{16}$ Following the 1994 Rwandan genocide, for example, Hutu genocidaires used food and other aid to purchase weapons and cement their own power, while denying food to their enemies. ${ }^{17}$ A less horrific but equally objectionable case occurred in Tamil Nadu, India, where, following the tsunami, the Indian government and international agencies provided aid according to caste, as the "untouchables" received little aid and were denied their basic rights. In such cases, the way aid is delivered undermines people's psychosocial well-being.

It is important for psychosocial workers to avoid reified images of "community" which are hopelessly simplistic. All aid, including psychosocial support, enters a conflict system where it is appropriated and used by different groups having different agendas. Considerable on-the-ground experience and understanding of the local culture and situation are needed to map the local power structure, discern different subgroups, and build a nondiscriminatory process that includes all groups, including invisibles such as the poorest of the poor and people with disabilities. For this reason alone, it is ill-advised for psychosocial workers who have no international emergency experience and little understanding of the local culture and situation to enter a disaster zone with the idea that "we just wanted to help and had to do something." If this type of approach is a recipe for coordination problems, it is equally a problem for the development of politically and culturally sensitive pro- 
grams. For these and other reasons, some professional psychology organizations discourage or prohibit their members from flooding into international disaster zones without affiliation with an appropriate aid structure or organization, relevant cultural competencies, and experience working in armed conflicts or natural disasters, whichever is appropriate in the situation.

Recent trends toward the politicization of aid and integrated military-humanitarian operations challenge the principles of independence and impartiality. ${ }^{18}$ In fact, the US government has announced that its humanitarian assistance is an arm of its foreign policy, which is far from impartial, and USAID now sits under the US State Department. In countries such as Afghanistan, aid is increasingly funded through provincial reconstruction teams. The activities of these civil-military units blur the boundaries between military and humanitarian operations, shrink the humanitarian space, and reduce local people's trust of humanitarian workers. Lost trust is a profound issue for psychosocial workers since feelings of trust and security are essential for healing and other key psychosocial tasks. For this reason, psychosocial workers need to think carefully about whether and how to position themselves relative to military operations. These decisions go beyond the traditional questions such as whether it is appropriate to hire armed guards, which can support the militarization that fuels armed conflicts. Most psychology curriculi offer little if any training on how to engage with these complex humanitarian ethical dilemmas.

\section{Assessment Issues}

An essential first step in addressing humanitarian needs is to conduct a careful situation assessment that examines not only the local needs but also the resources and assets of the affected group. For most humanitarian workers and agencies, assessments are means of collecting the data needed to guide effective programming and to inform proposals to donors. Unfortunately, the assessment process often raises local people's expectations that they will soon receive aid, ${ }^{19}$ but delays of several months between the assessment and the start of the program commonly occur and frustrate local people who have urgent needs. As a cynical Kosovar elder said to me, "They [the NGOs] came with their fancy cars and their writing tablets and asked many questions. But what have they actually done?" This frustration is amplified by the poor coordination that enables duplicate assessments, assessment fatigue, and ongoing inaction.

Furthermore, most assessments include little real participation by local people, who are relegated to roles such as "beneficiaries" and "respondents" to prepackaged questions rather than partners in taking stock of the situation and designing supports. Too often, assessments begin a process that quietly diminishes local people's agency at the moment when they most need to reassert control over their situation. Not a small side effect is the lost opportunity to learn about the culturally constructed understandings local people have about the emergency and its aftermath. As discussed below, this inattention to local cultural understandings serves to marginalize the local culture and meanings that themselves provide psychosocial support.

To avoid these problems, psychosocial workers should make participatory rapid assessments coupled with a rapid response that provides the tangible evidence of support that local people need to see. By continuing the assessment as the rapid response occurs, one circumvents the limitations of rapid assessments while avoiding long delays in response.

\section{Short-term Assistance}

In most emergencies, there is an influx of outside psychologists who, in the eyes of local people, seem to "parachute in, stay a short time, and leave." Short visits are valuable when they support and build the capacity of local teams and are in the context of an organization having a durable presence. However, this tidy picture often bears little resemblance to what actually happens. In Angola during its war of nearly forty years, some psychosocial workers flew in and spent a week or two conducting discussions intended to begin a process of support, expression, and healing. When they left, there was no one and no organization to follow up on the discussions, which had raised difficult issues and left some people feeling vulnerable. In such situations, the psychosocial interventions probably caused more harm than good and were ethically dubious at best.

A better role for outside psychologists is to build the capacity of local people and groups, leaving direct intervention to local people. ${ }^{20}$ Here, too, short-term efforts are best regarded with caution. For example, in many emergencies, NGOs and governments train cadres of local people to be counsellors. Not uncommonly, the trainings last only several weeks, and subsequent clinical supervision and support is an afterthought. The risk is that people having serious problems, including suicidal inclinations, may be in the care of people who are poorly equipped to support them and who may unintentionally cause harm. Because significant amounts of time are required to build capacities for psychosocial support, long-term efforts are indicated.

The need for long-term approaches stands in stark contrast with most donors' short funding cycles, which typically run only a year. In this respect, doing or supporting advocacy for long-term assistance is an essential part of responsible psychosocial work in emergencies. 


\section{Imposition of Outside Approaches}

The structure of the humanitarian industry creates enormous potential for quiet abuses of power that are evident in neo-colonialist practices by NGOs and other outside agencies. ${ }^{21}$ In many emergencies, NGOs rely on experts who use Western theory and practice, believe that their concepts and tools are universal and reflect good science, and analyze and offer possible solutions to the problem. In the process, local people take a secondary position and are made dependent on the outside experts, thereby sending a highly disempowering message that local people are unable to address local problems. In places such as sub-Saharan Africa, this message reinforces internalized beliefs about the inferiority of local people that centuries of colonialism had promulgated.

The problems inherent in this approach, however, extend well beyond issues of dependency and felt inferiority. In many emergencies, large numbers of psychologists arrive and set about measuring trauma prevalence, following the assumption that significant numbers of survivors will suffer clinical issues such as Post-Traumatic Stress Disorder (PTSD). The tendency of psychosocial workers to rush in with a singular trauma focus itself has a number of harmful effects. Too often, the focus on trauma narrows the development of comprehensive services for people who face mental health issues, including chronic mental illnesses and neurological disorders that had antedated the emergency. Quite often, the emphasis on trauma stigmatizes local people by using labels regarded locally as denigrating and by portraying normal reactions to life-threatening experiences as a form of pathology.22 Also, the power dynamics of the situation encourage the imposition of outsider concepts and tools that do not fit the local culture and that silence local people's own understandings about mental health and psychosocial well-being. Each culture has its own categories of life and death, illness and health through which people construct their understandings of their situation and what is required for recovery and well-being. The importance of culture is a prominent feature of many frameworks of psychosocial support. ${ }^{23}$ When outside experts arrive, however, carrying predefined questionnaires and looking mainly for what their Western theories predict, they typically fail to ask about the aspects of experience or practices that local people regard as most important.

To illustrate, a team of Angolan social workers in Christian Children's Fund (CCF)/Angola worked to reduce trauma following the 1994 Lusaka Protocol that brought a temporary breathing space in the Angolan wars. Having been trained by Western psychologists, they measured prevalence of trauma symptoms and changes in prevalence as a result of a community-based program of nonformal education, which included expressive activities such as song, dance, and story-telling. They were quite convinced that trauma was the problem and a Westernized process of emotional expression and "working through" was the remedy. This tidy picture was challenged by the story of a young girl who said her village had been attacked and her parents killed, causing her to flee for her life. But her biggest selfreported stress was her failure to have conducted the locally appropriate burial rituals. Questioned about this, she explained to a university-educated, relatively colonialized staff that where she lived, people believed that the conduct of the burial rituals is necessary for the dead people's spirits to transition to the realm of the ancestors. Without the rituals, the spirits would be trapped and upset, leading them to cause problems of bad health and misfortune for family and community. In stark contrast to Western psychological theories, which are cultural products that embody Enlightenment values such as individualism, she viewed herself as having a spiritual affliction that was communal rather than individual. She said she needed to talk with a healer who knew how to help her conduct the appropriate burial ritual. Fortunately, the CCF/Angola team took her advice, and the conduct of the burial ritual helped her significantly. The team subsequently reoriented its program to include ethnographic research and a combination of Western and local resources for purposes of healing.

Unfortunately, this scenario of learning from local people, which ought to be the norm, is an exception in most emergencies. Outside experts and agencies wield so much power in emergencies that they readily impose their own views without challenge. Making matters worse, local people often silence themselves or willingly embrace the idea that "we are traumatized" because it seems to be their best hope of obtaining outside assistance. The quiet marginalization of local culture undermines or devalues local resources that could have been built upon and that ordinarily provide a source of meaning and continuity. ${ }^{24}$ In this manner, outsiders privilege their own approaches while eroding or side-stepping valuable local sources of psychosocial support.

The best antidote to these problems of cultural imperialism is to learn as much as possible about the local cultural beliefs and practices before initiating even an assessment. ${ }^{25}$ Quite often, local healers, elders, and religious and civic leaders are helpful cultural informants who can provide valuable insights into local culture. In beginning assessment and other phases of the program cycle, it is valuable to work through local people who have a thorough understanding of the situation and culture. The focus should be less on outsiders' preconceptions than on local people's understandings and resources for psychosocial support. Also, it is useful to reframe one's role from that of outside 
expert, trainer, or program designer to that of facilitator in which one works in partnership with local people, learning together with them. Often, this approach leads to a constructive blending of local and outsider approaches that avoids sidelining local practices. Throughout, it is crucial for psychosocial workers to reflect critically on the power dynamics of the situation and what they have done or ought to do to respect and valorize local culture. Because some local practices are harmful, a key part of maintaining a critical perspective is to avoid the romanticization of local culture and to use international human rights standards as benchmarks for deciding which local practices are unsupportable.

\section{Protection Issues}

Protection is a profound issue for internally displaced people, many of whom live in very dangerous situations but do not enjoy the same standard of international protections extended to refugees. For example, the risks of child recruitment increase in situations of mass displacement. Although discussions of protection frequently focus on physical safety, protection also has to do with reducing emotional, social, and spiritual threats to well-being. Five key protection issues merit attention here.

First are breaches of confidentiality, which can increase physical and psychosocial vulnerability. Imagine, for example, a psychosocial worker interviewing a girl formerly associated with an armed group in order to learn how to most effectively support her reintegration. The interview, however, ignites much discussion in the village, and word spreads to a neighbouring village. Soon thereafter, the girl is reabducted by the armed group. This example, which resonates with actual events in the field, illustrates the difficulties of maintaining confidentiality in a small village in which life is highly collectivistic, norms of Western privacy and confidentiality are weak, and the arrival of an outsider is a major event. To prevent such problems, it is vital to exercise high levels of sensitivity and to learn from key local informants such as elder women what steps can be taken to protect confidentiality.

Second are issues of informed consent. Before interviewing war-affected people, most psychosocial workers seek to obtain their informed consent by explaining their purpose, asking their written permission to talk with them, and explaining their right to refuse the interview, to not answer particular questions, or to end the interview at any time. The idea of written permission is often problematic if most people are illiterate, though the use of thumbprints or related methods may be suitable substitutes. However, the deeper question is whether local people really feel free to say "No." People in collectivist societies view the group good as trumping the individual good, and this may lead them to do things that cause individual discomfort or harm. In desperate circumstances, the power dynamics of the situation strongly mitigate against saying "No" because the villagers see the interviewer as a source of cash and badly needed assistance. To refuse an interview might not only violate cultural norms of hospitality but also be perceived as harming one's family and village. As a result a person who is highly vulnerable might agree to participate in an interview when she is ill equipped to cope with the difficult feelings it may evoke. Although there is no easy remedy for this problem, useful steps are to discuss power issues directly and to seek guidance on how to handle the issues from local leaders and local groups working on social protection issues.

Third, interviews and psychosocial interventions may cause harm by asking intrusive questions that trigger horrific memories or by probing sensitive issues at a moment when the participants feel quite vulnerable. ${ }^{26}$ In Afghanistan, I encountered a young humanitarian worker who had limited psychosocial training but had learned that healing occurs through emotional expression. Each day he gathered groups of children and asked them to draw a picture of the worst thing that had happened to them during the war. Unfortunately, he had not learned the other side of that view, namely, that the expression needs to be coupled with safety and appropriate processing or "working through" under guidance by a trained psychologist or social worker and backed by careful supervision. Nor had he taken into account that serious psychological issues might not arise immediately but might surface one or several days later. Making matters even worse, he had made no provisions for follow-up support. Such ill constructed psychosocial work is likely to do more harm than good and constitutes a significant protection threat. To prevent such harm, it is useful to avoid aggressive questioning; to provide appropriate psychosocial support during and following interviews; to work with local helpers to identify who is not in a good position to participate in potentially troubling discussions; and to ensure that potentially invasive methods receive peer review by local protection experts and are backed by appropriate supervision.

Fourth is the problem of excessive targeting of at-risk groups. In many situations, psychosocial workers attempt to support at-risk people, such as children formerly associated with armed groups, by engaging them in communitybased programs that intermix elements such as community mobilization, family reintegration, health, education, and livelihoods. A major priority is to reduce the stigma often attached to being a former child soldier, many of whom had belonged to groups that had attacked the villages they hope 
to return to in the post-conflict environment. Although such holistic approaches have discernible benefits to the former child soldiers, they may also trigger jealousies and create reverse stigmatization. In countries such as Sierra Leone, villagers often asked, "Why are these people who had attacked us getting all this attention and wearing better clothes than everyone else in the village?" In Liberia, villagers often referred to the material benefits extended to former child soldiers but not to others as "blood money," a tacit reward for what they had done. Fortunately, such problems can be avoided through the use of integrated programs that offer support not only to a group such as former child soldiers but also to other children who are at risk due to issues such as separation, disability, forced early marriage, dangerous labour, and HIV/AIDS, among many others. $^{27}$

Fifth is the lack of connection between work on healing and nonviolent handling of conflict, which ought to go hand in hand. In Kosovo, following the Serb onslaught, the mass displacement of Kosovar Albanians, and the return home, much psychosocial work conducted in a traumahealing idiom entailed having groups of Kosovar Albanians tell their stories, expressing and "working through" their pain. Often, this work had no connection with nonviolent conflict management or resolution. Numerous participants in such group discussions said that as Kosovars told their horrific stories, people felt anger and desire for revenge since it was apparent who had caused their victimization and suffering. Some participants said they knew of people who had left the discussions in a rage and attacked Serbs, thereby increasing protection threats to the now minority group and deepening the social divisions that had fuelled much of the violence. To avoid such scenarios, it is vital to link expressive work on healing with work on nonviolent handling of inter-group conflict and on the social injustices in which armed conflict is rooted.

\section{Conclusion}

There are countless other ways in which psychosocial workers unintentionally cause harm. Harm sometimes occurs not through inappropriate psychosocial practices but through one's personal dress and demeanour. In Afghanistan, for example, female expatriates will give offense if they wear the sleeveless blouses and shorts that are appropriate everyday dress in places such as Europe and North America. Harm may result from the very structure of a large-scale humanitarian intervention. In Afghanistan, following the defeat of the Taliban in 2001, the influx of humanitarian workers from predominantly Christian countries fuelled local perceptions that the humanitarian effort was part of an organized effort to Christianize a fervently Muslim society. The fact that even one's presence, dress, and demeanour in a war zone may cause harm serves as a poignant reminder of the overarching importance of issues such as culture and religion in the current global context.

These and other issues warrant much greater attention to the "Do No Harm" imperative in the field of psychosocial assistance. Although some useful steps and guidelines are offered by the nascent global guidance referred to earlier, the problems are systemic and require concerted awareness and action at multiple levels and among a diversity of actors. New kinds of training and preparation are needed to provide the next generation of humanitarian workers with the ethical awareness, cultural competencies, understanding of historical and social forces, and technical skills they will need to respond to emergencies in a productive, appropriate manner. This new training cannot be achieved in academic institutions alone since actual field experience is often the best source of learning on these issues. Professional organizations and humanitarian agencies also need to provide better guidance and oversight. All agencies need to strengthen the evidence base regarding effective practice, simultaneously encouraging the use of effective practices and preventing the use of practices that are harmful and violate human rights. Above all, there need to be stronger norms of self-reflection and critical thinking among humanitarian workers. Collectively, these and related steps may enrich and transform the field of psychosocial assistance, enabling it to achieve its full potential and to provide the most effective support to war- and disaster-affected people in their hour of greatest need.

\section{Notes}

1. Abraham Maslow, Toward a Psychology of Being (New York: Van Nostrand, 1962), passim.

2. Kenneth Miller and Lisa Rasco, "An Ecological Framework for Addressing the Mental Health Needs of Refugee Communities," in The Mental Health of Refugees, ed. K. Miller and L. Rasco (Mahwah, NJ: Erlbaum, 2004); Neil Boothby, Alison Strang, and Michael Wessells, "Introduction," in A World Turned Upside Down: Social Ecological Approaches to Children in War Zones, ed. N. Boothby, A. Strang, and M. Wessells (Bloomfield, CT: Kumarian, 2006); Alastair Ager, "Perspectives on the Refugee Experience," in Refugees: Perspectives on the Experience of Forced Migration, ed. Alastair Ager (London: Pinter, 1999); Frederick Ahearn, "Psychosocial Wellness: Methodological Approaches to the Study of Refugees," in Psychosocial Wellness of Refugees: Issues in Qualitative and Quantitative Research, ed. F. Ahearn (New York: Berghahn, 2000); Maryanne Loughry and Carola Eyber, Psychosocial Concepts in Humanitarian Work with Children (Washington, DC: National Academies Press, 2002); Anthony Marsella, Thomas Bornemann, Solvig Ekblad, and John Orley, "Intro- 
duction," in Amidst Peril and Pain: The Mental Health and Well-Being of the World's Refugees, ed. Anthony Marsella, Thomas Bornemann, Solvig Ekblad, and John Orley (Washington, DC: American Psychological Association, 1994); Roberta Apfel and Bennett Simon, "Introduction," in Minefields in Their Hearts: The Mental Health of Children in War and Communal Violence, ed. R. Apfel and B. Simon (New Haven, CT: Yale University Press, 1996).

3. John Wilson, "Introduction," in Broken Spirits: The Treatment of Traumatized Asylum Seekers, Refugees, War and Torture victims, ed. J. Wilson and B. Drozdek (New York: BrunnerRoutledge, 2004); Boothby, Strang, and Wessells, 63-241; Nancy Baron, Soeren Buus Jensen, and Joop de Jong, "Refugees and Internally Displaced People," in Trauma Interventions in War and Peace: Prevention, Practice, and Policy, ed. B. Green, M. Friedman, J. de Jong, S. Solomon, T. Keane, J. Fairbank, B. Donelan, and E. Frey-Wouters (New York: Kluwer, 2003); Miller and Rasco, 67-334.

4. Jon Hubbard and Kenneth Miller, "Evaluating Ecological Mental Health Interventions in Refugee Communities," in K. Miller and L. Rasco, 337-374; Joan Duncan and Laura Arntson, Children in Crisis: Good Practices in Evaluating Psychosocial Programming (Westport, CT: Save the Children, 2004).

5. Inter-Agency Standing Committee, IASC Guidance on Mental Health and Psychosocial Support in Emergency Settings (Geneva: IASC, 2007).

6. Mary Anderson, Do No Harm: How Aid Can Support Peace-Or War (Boulder, CO: Lynne Rienner, 1999), 1-3; John Prendergast, Frontline Diplomacy: Humanitarian Aid and Conflict in Africa (Boulder, CO: Lynne Rienner, 1996), 17-42; Carlos Martin Beristain, Humanitarian Aid Work: A Critical Approach (Philadelphia: University of Pennsylvania Press, 2006), 96-98.

7. Larry Minear, The Humanitarian Enterprise: Dilemmas and Discoveries (Bloomfield, CT: Kumarian, 2002), 1-8.

8. Michael Wessells, "Culture, Power, and Community: Intercultural Approaches to Psychosocial Assistance and Healing," in Honoring Differences: Cultural Issues in the Treatment of Trauma and Loss, ed. K. Nader, N. Dubrow, and B. Stamm (New York: Taylor \& Francis, 1999), 267-282.

9. Beristain, 110-142.

10. Minear, 75-98.

11. Ibid., 19-36.

12. Duncan and Arntson, 19.

13. Inter-Agency Standing Committee, Growing the Sheltering Tree: Protecting Rights through Humanitarian Action, $<\mathrm{http}$ //www.icva.ch/cgi-bin/browse.pl?doc=doc00000717> (accessed November 8, 2006).

14. Minear, 55-74; Neil Boothby, "Mobilizing Communities to Meet the Psychosocial Needs of Children in War and Refugee Crises," in R. Apfel and B. Simon, 149-164; Michael Wessells,
Child Soldiers: From Violence to Protection (Cambridge, MA: Harvard University Press, 2006), 181-218.

15. Inter-Agency Standing Committee, IASC Guidelines on Mental Health and Psychosocial Support in Emergency Settings, Action Sheet 5.1, 95.

16. G. Anderson, 8-53; Prendergast, 17-35; Michael Maren, Road to Hell: The Ravaging Effects of Foreign Aid and International Charity (New York: Free Press, 1997).

17. Prendergast, 20-21.

18. Michael Wessells, "Negotiating the Shrunken Humanitarian Space: Challenges and Options," in Handbook of International Disaster Psychology, vol. 1, ed. G. Reyes and G. Jacobs (Westport, CT: Praeger, 2006).

19. Deanna Beech, "Peace-Building, Culturally Responsive Means, and Ethical Practices in Humanitarian Psychosocial Interventions," in Reyes and Jacobs, 98-99.

20. Inter-Agency Standing Committee, IASC Guidelines on Mental Health and Psychosocial Support in Emergency Settings, Action Sheet 4.1.

21. Vanessa Pupavac, "Humanitarian Politics and the Rise of International Disaster Psychology," in Reyes and Jacobs, 15-34; Andy Dawes and Edward Cairns, "The Machel Study: Dilemmas of Cultural Sensitivity and Universal Rights of Children," Peace and Conflict: Journal of Peace Psychology 4, no. 4 (1998): 335-348.

22. Patrick Bracken, "Hidden Agendas: Deconstructing PostTraumatic Stress Disorder," in Rethinking the Trauma of War, ed. P. Bracken and C. Petty (London: Free Association Book, 1998), 38-59; Derek Summerfield, "A Critique of Seven Assumptions behind Psychological Trauma Programmes in War-affected Areas," Social Science and Medicine, 48 (1999): 1449-1462; Wessells, 1999.

23. Alastair Ager, "Toward a Consensus Protocol for Psychosocial Response in Complex Emergencies," in Reyes and Jacobs.

24. Wessells, Child Soldiers, 146-153.

25. Wessells, 1999, 275-280.

26. Beech, 97.

27. Wessells, Child Soldiers, 204-205.

Michael G. Wessells, PhD, is professor of clinical population and family health at Columbia University and senior advisor on child protection for Christian Children's Fund. He organizes community-based programs of psychosocial assistance and child protection in over thirty countries, and was co-chair of the IASC Task Force on Mental Health and Psychosocial Support in Emergency Settings, which officially ended December 31, 2007. 